\title{
A study of the medical causes of absence from duty aboard South African merchant ships
}

\author{
SAMUEL LEVY \\ Norwich House, Cape Town, South Africa
}

Levy, S. (1972). Brit. J. industr. Med., 29, 196-200. A study of the medical causes of absence from duty aboard South African merchant ships. Over a period of four and a half years 556 instances occurred in which crew members were put off duty on medical grounds for a period of four or more days. Illness accounted for 297 cases whereas accidents were responsible for 259 cases. Illness and accident cases were off duty for an average period of 28 and 34 days respectively. Slightly more working days were thus lost on account of accidents. Admission to hospital was required in $90 \%$ of illnesses compared with only $36 \%$ of accidents.

Appendicitis (of questionable veracity), peptic ulceration, and psychiatric disturbances were among the more common causes of incapacity.

Forty percent of accidents occurred on deck and in the cargo holds. Fractures occurred most commonly in the upper limbs, especially the hand. Eleven percent of the accidents occurred ashore, mostly due to assault.

Further study is required to elucidate whether the emotional problems encountered are brought to sea by the personnel or are a result of life on board ship. The high incidence of accidents stresses the fact that a sea career is one of the more dangerous occupations.

With improved medical care and better living and working conditions on board merchant ships the frequency of serious disease at sea has been dramatically reduced. The pattern of disease has changed from an emphasis on battle wounds in the old armed merchantmen (Blane, 1785) and deficiency diseases, such as scurvy (Lind, 1757) through the infectious diseases to modern times when trauma, of a different origin, once again appears as one of the major causes of lost working time.

In a previous survey (Levy, 1969) it was found that the more serious illnesses and accidents on board merchant ships, which required an off duty period of four or more days, accounted for $4.8 \%$ of medical consultations. The aim of this survey is to demonstrate the modern spectrum of these more serious illnesses and accidents occurring on board South African merchant ships. 
seaman rejoined the same or another ship of the fleet the full medical examination was repeated and the previous year's medical history was carefully checked. During the seaman's stay on board ship any medical complaint, as well as the consulting doctor's diagnosis and treatment, was noted on a special medical history card by a designated navigating officer who was responsible for medical care aboard ship. This history card was transferred with the seaman from ship to ship over the years and was also presented at re-employment medical examinations. Qualified medical attention could be obtained only at ports of call, but medical advice was available at all times through radio communication.

This study is based on data included in accident and illness reports returned to head office in Cape Town by the ship's master and attending physicians at various ports of call.

\section{Results}

During the period of study there were 556 instances in which crew members were off duty for four or more days. Of this total, 297 cases were the result of illness and 259 cases were the result of accidents. Table 1 illustrates the relationship between the period off duty and the number of cases involved.

Off duty periods in accident cases were calculated as from the day the patient stopped work, whether aboard ship or ashore, until he was declared fit for duty by the attending physician. In the case of illness, off duty periods were calculated from the day of stopping work until the patient was declared fit for duty by the attending physician or, very rarely, if the patient was repatriated home, until the day he arrived in his home port. Repatriation home by sea or air for any illness was strongly discouraged so as to avoid illness being wrongly used as an excuse for getting home. The length of off duty periods in foreign ports was occasionally prolonged by a few days because the crew member was waiting to rejoin the same or another ship of the fleet. Because of these difficulties the off duty period is not an accurate reflection of the seriousness of the individual illness or accident but demonstrates the number of working

TABLE 1

Relationship of Number of CASES AND TiMe OFF DUTY

\begin{tabular}{rrrr|r|r|r}
\hline \multicolumn{3}{c|}{ Days off duty } & & Accident & Illness & Total \\
\hline $4-10 \ldots$ & $\ldots$ & $\ldots$ & $\ldots$ & 51 & 59 & 110 \\
$11-20 \ldots$ & $\ldots$ & $\ldots$ & $\ldots$ & 51 & 99 & 150 \\
$21-30 \ldots$ & $\ldots$ & $\ldots$ & $\ldots$ & 43 & 48 & 91 \\
$31-60 \ldots$ & $\ldots$ & $\ldots$ & $\ldots$ & 88 & 66 & 154 \\
$61-90 \ldots$ & $\ldots$ & $\ldots$ & $\ldots$ & 10 & 19 & 29 \\
More than 90 & $\ldots$ & $\ldots$ & 16 & 6 & 22 \\
\hline Total & $\ldots$ & $\ldots$ & $\ldots$ & 259 & 297 & 556 \\
\hline
\end{tabular}

days lost to the shipping company. The average off duty period due to illness was 28 days, whereas in accident cases it was 34 days.

Of the illness cases who were put off duty for four or more days $90 \%$ were thought serious enough for the crew member to be 'signed off' his ship and be admitted to hospital for treatment. Only $36 \%$ of accident cases were admitted to hospital, the remainder being treated on board ship.

Eight deaths occurred during the period of study. Two deaths were the result of drowning, two crew members died of asthma, and two of coronary thrombosis. One crew member died of multiple injuries after a fall from the masthead and one died of bronchial carcinoma.

The calculation of the exact incidence of disease was made virtually impossible by the constant change in personnel for leave and health reasons.

\section{Illness}

The illnesses which occurred in this survey are listed in Table 2 and will be discussed under their separate headings.

Central nervous system Psychiatric illness occurred far more frequently in officers than in ratings. The reason for this may lie in their completely different background and aspirations.

The psychoneuroses occurred as often as the psychoses. Although alcohol consumption is known to be high on board merchant ships, alcoholism was not a common medical problem on our ships. Alcohol appeared to be used as a tranquillizer for the emotional problems of shipboard life.

Of the psychoses, depressive psychosis was the most common diagnosis, being four times as frequent as schizophrenia. Most of the psychotic patients had a history of previous admission to a psychiatric hospital before breaking down at sea. Psychiatric illness occurred as frequently on cargo ships as on bulk oil carriers.

Respiratory tract The low incidence of pulmonary tuberculosis as compared to that found in other surveys (Hutchison, 1943; Barclay and Gray, 1958) demonstrates the value of regular medical examinations.

Asthma is definitely a dangerous disease at sea. Two of the four cases noted ended fatally. One rating died aboard before his ship reached port, and an officer died in hospital ashore.

Cardiovascular system The only notable fact in this category is the higher incidence of coronary heart disease in the officers. This may be explained by their average age being higher and by their greater responsibilities, but it is likely due to a known 
TABLE 2

Classification of Illness causing Lost Time

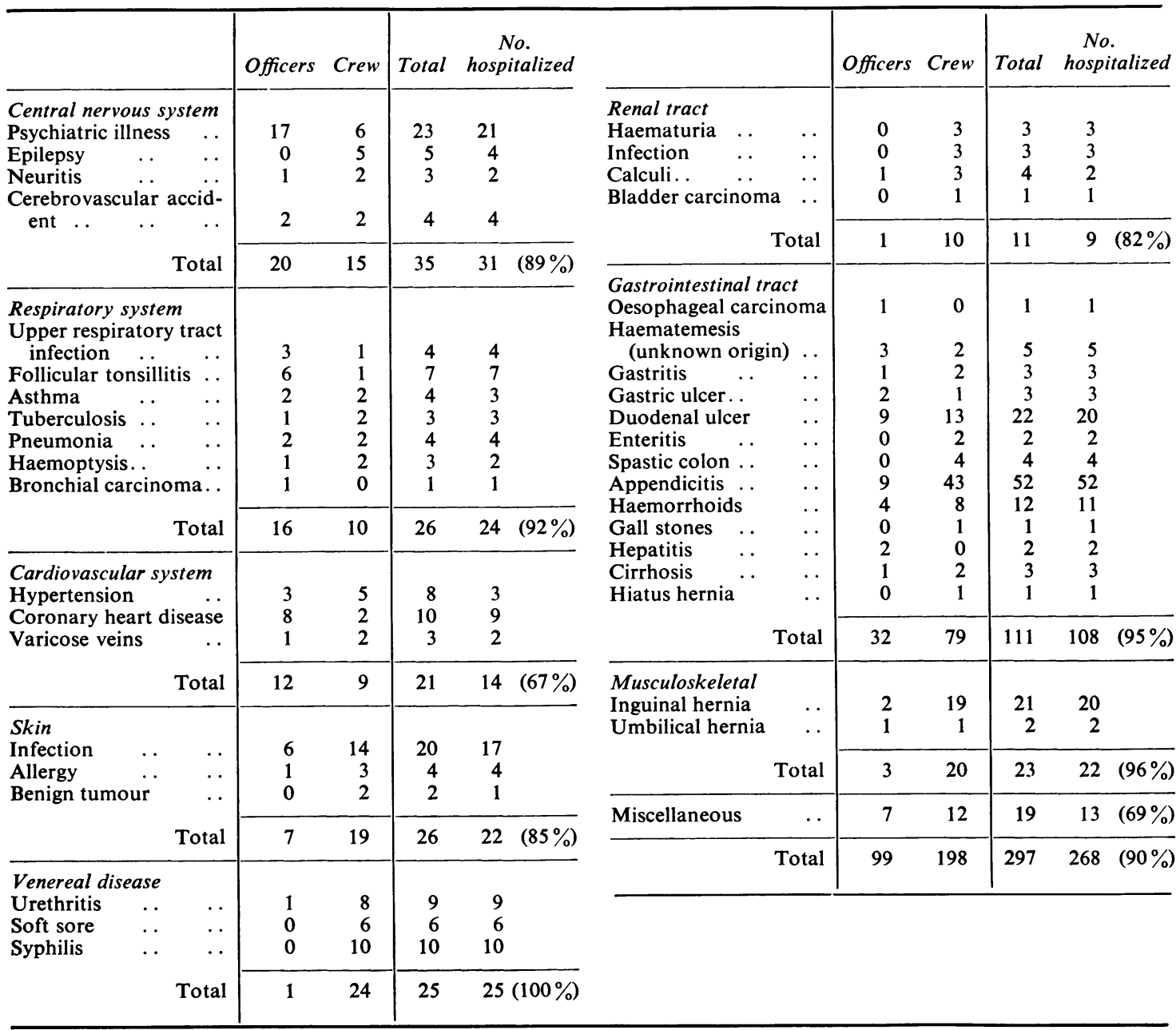

difference in racial incidence (Schrire, 1966) as the officers are of European extraction and the ratings are drawn from the Cape coloured population.

Skin Although crew members suffer from allergic dermatitis more often than from skin infection such as boils, abscesses, and cellulitis, these skin infections are shown to be more serious in that they resulted in a greater loss of working days.

Venereal disease It is well known that urethritis occurs more frequently than penile sores. The larger number of cases with penile sores hospitalized, however, reflects the seamen's dread of syphilis as a contagious disease. It is very often on the captain's insistence that these men are unnecessarily hospitalized for treatment.

Intestinal tract In this section a few interesting facts came to light. Approximately one third of all cases studied occurred in this category.

The frequency of operations for appendicitis in both officers and ratings is much higher than the incidence of appendicitis occurring in people living and working ashore. It is hardly likely that all these patients suffered genuine acute attacks. From the histories available it seems that most of these cases presented with pain in the right iliac fossa due to enteritis or, more likely, spastic colon. The attending doctor often has to make an immediate decision with 
little time for observation before the ship sails. He may also be influenced by the ship's captain who, quite rightly, would prefer to leave a doubtful case of appendicitis ashore in hospital. Because of the frequency of appendicectomy for the symptom of right iliac fossa pain, it appears as if the doctors in the various ports of call recognize the seaman's fear of developing appendicitis in mid-ocean and would rather perform a simple operation than leave the patient with his fear of a future attack. This fear is very apparent in that seamen with pain over the appendix area often visit doctors in successive ports until an appendicectomy is performed.

The second largest group of patients were those suffering from duodenal ulcer. Officers and ratings, despite different background and education levels, appear to be affected equally. This suggests common aetiological factors such as excessive smoking, drinking, diet, lack of exercise, and possible similar emotional stresses and reactions.

Musculoskeletal Although each crew member is specifically examined for the presence of inguinal hernia during his annual medical examination, the number of these hernias occurring is surprisingly high. The fact that inguinal hernia occurs commonly in seamen has been noted by other authors (Hutchison, 1943; Barclay and Gray, 1958). As this occurs more frequently in ratings, their heavier manual work may be a contributing factor.

Miscellaneous This group included cases of phimosis requiring circumcision, otitis, eye infections, collagen disease, blood dyscrasia, and glandular fever.

\section{Accidents}

Table 3 demonstrates the relative frequency and seriousness of the accidents resulting in off duty periods of four or more days. Of the 259 accidents listed, $40 \%$ occurred on deck and in the cargo holds, $33 \%$ in the accommodation, $16 \%$ in the engine room, and $11 \%$ occurred ashore.

Upper limb fractures occurred most frequently in the smaller bones of the hand, the majority being the result of hands caught in slamming doors. Fractures of the lower limbs usually involved the large bones. Here the primary causes were falls on deck and down stairs.

Serious burns occurred only slightly more frequently in the engine room than in the galley.

Eye injuries were all due to corneal foreign bodies as a result of chipping paint or rust without the use of protective goggles.

Head injuries were most often due to a fall on deck or in the accommodation and were usually nothing more than a scalp laceration or mild concussion. Back injuries were largely diagnosed as bruises and sprains
TABLE 3

Classification of Accidents causing Lost TIME

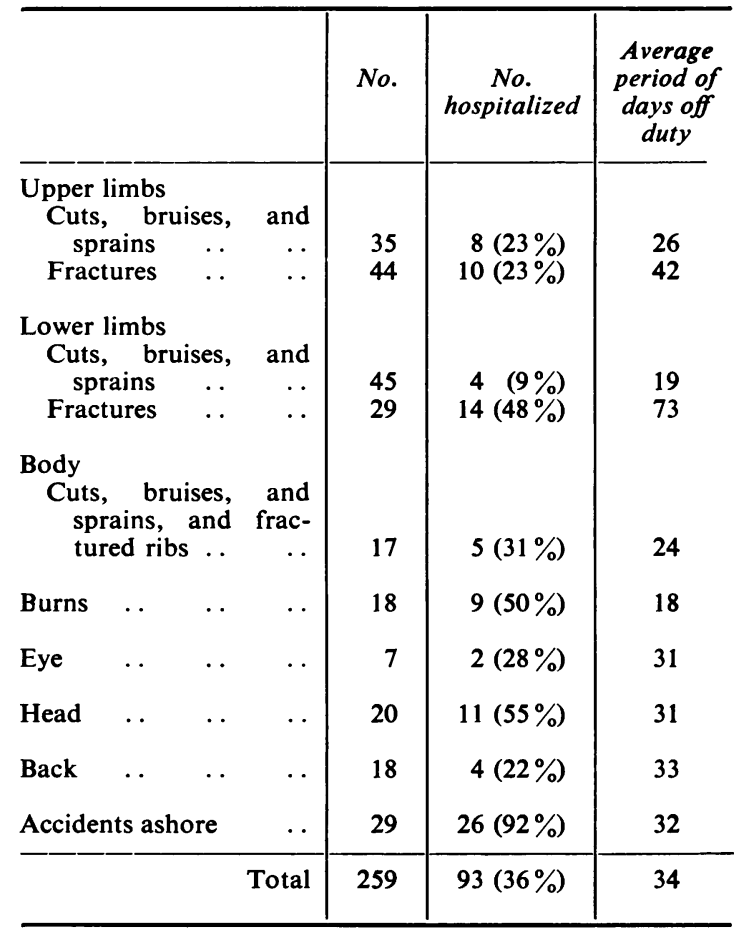

and were once again due mainly to falls rather than to the lifting of heavy objects.

A surprisingly large number of accidents occurred ashore. Of these, $60 \%$ were the result of ratings being assaulted. Motor vehicle accidents were next in frequency; officers and ratings were equally involved. As stated in Table 3, 92\% of these accident cases were hospitalized for an average period of 32 days, an extremely serious cause of loss of working days.

Table 4 is self explanatory and is included to show the frequency of medical emergencies which the ships' officers felt they could not manage alone and therefore could not wait until the next scheduled port. The ship was thus deviated off course to the nearest port to obtain qualified medical attention.

\section{Conclusion}

Some sources still consider venereal disease and alcoholism as the major illnesses occurring in seamen. This survey and other recent studies (Ellis, 1969; Otterland, 1960) prove this to be a fallacy and show that emotional disturbances, psychoses, psychoneuroses, and psychosomatic diseases are among the most important causes of serious medical disability and lost working days. 
TABLE 4

\section{Deviation for Medical Emergencies}

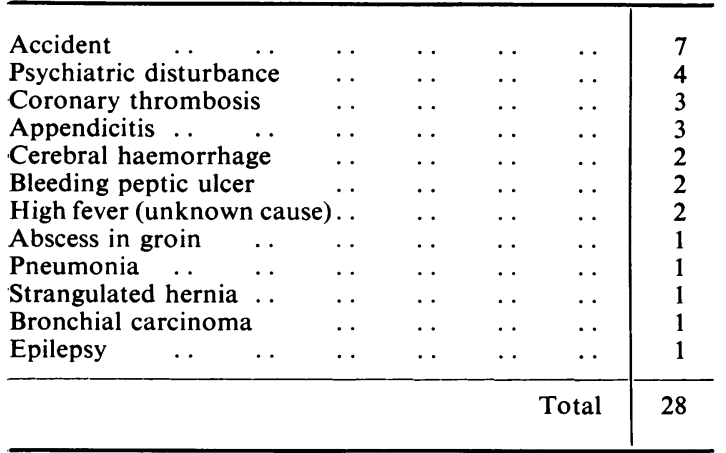

Whether the high incidence of emotional problems is due to the type of person going to sea, or perhaps to the peculiarities of shipboard life, is yet to be solved. A recent study (Tuft and Berman, 1970) suggests psychiatric similarities within the mercantile marine population and favours the theory that the type of individual who distrusts interpersonal relationships chooses the sea as a career.

The frequency of lost working time as a result of accidents is also in keeping with recent surveys (Hutchison, 1943; Hutchison, 1969). The sea as a calling has been classified as the most dangerous of all group occupations except soldiering on active service (Carr, 1945).

It is hoped that this survey will be of value in demonstrating the modern pattern of medical problems at sea and so give direction to the preventive measures which are obviously necessary. The time has now come to employ modern vocational psychological techniquesin establishing the character- istics of a good seaman. 'This profile should then be used in selecting sea-going personnel. The mechanical causes of accidents should be noted and active steps taken in correcting them as far as possible. Once again full use should be made of psychological techniques in promoting awareness of the accident problem and its causes.

I wish to thank the Managing Director, Mr. M. de W. Marsh, and all personnel of the South African Marine Corporation for their kind assistance and co-operation in making this survey possible.

\section{References}

Barclay, R. W., and Gray, E. A. (1958). Health problems of American seamen as measured by hospital statistics. Publ. Hlth Rep. (Wash.), 73, 585-589.

Blane, G. (1785). Observations on the Diseases of Seamen. London.

Carr, G. J. (1945). Health problems in the Merchant Navy. Brit. J. industr. Med., 2, 65-73.

Ellis, F. P. (1969). The health of the Navy: the changing pattern. Brit. J. industr. Med., 26, 190-201.

Hutchison, A. (1943). Incapacitating sickness among merchant seamen. Lancet, 2, 741-742.

- (1969). Health problems of seafarers. Roy. Soc. Hlth J., 89, 117-121.

Levy, S. (1969). A survey of sea diseases on South African ships. S. Afr. med. J., 43, 1079-1082.

Lind, J. (1757). An Essay on the Most Effectual Means of preserving the Health of Seamen in the Royal Navy. London.

Otterland, A. (1960). A Sociomedical Study of the Mortality in Merchant Seafarers. Acta med. scand., 167, Suppl. 357.

Schrire, V. (1966). Clinical Cardiology, 2nd ed. Staples Press, London.

Tuft, L. H., and Berman, M. I. (1970). Some preliminary observations on a psychiatric inpatient merchant seaman population using the MMPI. Sth. med.J. (Bgham, Ala), 63, 72-76.

Received for publication June 25, 1971. 